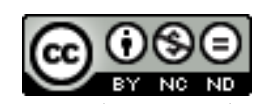

Protestantismo em Revista é licenciada sob uma Licença Creative Commons.

http://dx.doi.org/10.22351/nepp.v44i2.3605

\title{
Religiosidade de adolescentes da região de fronteira
}

\author{
Religiosity of adolescents in the border region
}

\author{
Maria Luzia da Silva Santana* \\ Édna Leandro da Silva** \\ Marcelo Máximo Purificação***
}

\begin{abstract}
Resumo
A religiosidade na adolescência pode se configurar como uma experiência singular, pessoal e individual que é resultado das vivências do adolescente em diferentes contextos, a exemplo da família, vizinhança, grupo de amigos, colegas de escolas que frequentam instituições religiosas ou não. Não é simplório colocar em diálogo as questões que perpassam a temática da religiosidade no contexto escolar, notadamente marcado pelo multiculturalismo, com estudantes oriundos de diferentes nacionalidades, com diversidade de idiomas, culinária, religião, dentre outros elementos que são próprios de cada cultura. Assim, a presente pesquisa tem o objetivo de descrever a religiosidade de adolescentes no contexto de fronteira seca, na cidade de Ponta Porã/Brasil que faz divisa com Pedro Juan Caballero/Paraguai. Para isso, foram aplicados o Questionário de Dados Sociodemográficos e a Escala de Religiosidade da Duke com vinte e seis (26) estudantes, sendo doze (12) do sexo masculino e quatorze (14) do sexo feminino, com idades entre 12 e 13 anos, de uma turma do $7^{0}$ Ano do Ensino Fundamental I de uma escola estadual, localizada na cidade de Ponta Porã e próxima à faixa de fronteira. De maneira geral, os dados apontaram que os adolescentes participantes deste estudo, no contexto da referida fronteira frequentavam instituições religiosas, acreditavam em Deus, realizavam ritos e se esforçavam para vivenciar a religião em todos os aspectos de sua vida. Neste sentido, a religiosidade é um elemento que perpassa a vivência dos adolescentes, pois a maioria frequentava instituições de caráter religioso, dedicava a preces e orações e se esforçava para viver sua vida conforme os preceitos religiosos.
\end{abstract}

\section{Palavras-chave}

Adolescentes. Escola. Região de Fronteira. Religiosidade.

[Texto recebido em janeiro de 2018 e aceito em janeiro de 2018, com base na avaliação cega por pares realizada por pareceristas ad hoc]

* Mestra em Psicologia. Doutoranda em Psicologia (Universidade Católica de Brasília). Professora da Universidade Federal do Mato Grosso do Sul (UFMS). E-mail: maria.s.santana@ufms.br

** Graduada em Pedagogia (UFMS). Email: edna.silva5666@gmail.com

*** Doutor em Ciências da Religião (PUC/GO). Professor do Centro Universitário de Mineiros. E-mail: maximo@fimes.edu.br 


\begin{abstract}
Religiosity in adolescence can be configured as a unique, personal and individual experience which is the result of the experiences of the adolescent in different contexts, assimilating the example of the family, neighborhood, group of friends, school classmates who frequent religious institutions or not. It is not a simple matter to place in dialog the issues which permeate the theme of religiosity in the school context, notably marked by multiculturalism, with students coming from different nationalities, with diversity of languages, culinary, religion, among other elements which are specific to each culture. Thus, the goal of this research is to describe the religiosity of adolescents in the context of the dry border, in the city of Ponta Porã/Brazil which borders with Pedro Juan Caballero/Paraguay. To do this, the Socio-demographic Questionnaire and the Duke Scale of Religiosity were applied with twenty-six (26) students, being twelve (12) male and fourteen (14) female, ages 12 to 13, of a class of the 7th grade of Elementary Education I of a state school, located in the city of Ponta Porã and near the border strip. In general, the data showed that the adolescents participating in this study, in the context of the referred borderline, frequented religious institutions, believed in God, carried out the rituals and worked at living out their religion in all aspects of their life. In this sense, religiosity is an element which permeates the life experience of the adolescents, since the majority frequented religious institutions, dedicated themselves to supplications and prayers and worked at living their lives according to the religious precepts.
\end{abstract}

\title{
Keywords
}

Adolescents. School. Border Region. Religiosity.

\section{Introdução}

A adolescência é vista como uma criação humana, com representação, fato social, psicológico e significado resultados da cultura e linguagem que permeiam as relações sociais. ${ }^{1}$ A adolescência é compreendida como uma construção social que tem suas repercussões na subjetividade e no desenvolvimento do homem moderno, sendo, portanto, significada, interpretada e construída pelos homens. A busca da compreensão do que é a adolescência implica entender sua gênese histórica e seu desenvolvimento. ${ }^{2}$

A abordagem sócio-histórica, ao discutir sobre esse período da vida, não faz o questionamento: o que é a adolescência?, mas sim, como ela se constituiu historicamente? Assim, a adolescência é compreendida como resultado de uma construção social e histórica, por isso não é algo acabado, que tem um início e um fim bem demarcado, e nem um modelo a ser seguido.

1 OZELLA, S. Adolescência: uma perspectiva crítica. In: CONTINI, M. L. J.; KOLLER, S. H. (Orgs.). Adolescência e psicologia: concepções, práticas e reflexões críticas. Rio de Janeiro: CFP, 2002. p. 16-24. Disponível em: <http://site.cfp.org.br/wp-content/uploads/2008/01/adolescencia1.pdf>. Acesso em: 15 abr. 2012.

2 BOCK, A. M. B. A adolescência como construção social: estudo sobre livros destinados a pais e educadores. Psicologia Escolar e Educacional, Campinas, v. 11, n. 1, p. 63-67, jan./jun. 2007. Disponível em: <http://www.scielo.br/pdf/pee/v11n1/v11n1a07.pdf>. Acesso em: 14 jan. 2012. 
A definição dessa fase da vida humana ultrapassa aspectos cronológicos e biológicos e esbarra em condições sociais, culturais, históricas e psicológicas específicas ${ }^{3} \mathrm{e}$ a diversidade de elementos que influenciam o desenvolvimento do adolescente the possibilita vivenciar esse período de maneira singular. A partir dessas ideias, considera o desenvolvimento do adolescente como um fenômeno multifacetado que envolve questões biológicas, características do contexto histórico, social e cultural, as organizações, ideologias e crenças que influenciam direta e/ou indiretamente o adolescer.

A religiosidade é vivenciada pelos adolescentes e pode ser um dos elementos marcantes de sua singularidade. Cabe pontuar que há diferença entre a religião e a religiosidade - que são fenômenos que marcam a vida humana desde os primórdios da humanidade. Entende-se que a "religião é um sistema comum de crenças e práticas relativas a seres humanos dentro de universos históricos e culturais específicos" sendo que nesse conceito devem ser considerados os mais diversos fenômenos religiosos. ${ }^{4}$

Toma-se a noção de religiosidade como uma experiência pessoal e individual de espiritualidade, construída a partir de vivências anteriores em instituições religiosas e fora delas. Desta forma, ela se diferencia do conceito de religião. A religião, de caráter mais institucional, teria uma influência profunda na forma de organizar a existência humana, já que ela se afirma para além daquilo que é material, natural, concreto e finito. ${ }^{5}$

Para delimitar a discussão em torno da religiosidade de adolescentes, cabe pontuar que a religiosidade nessa fase de desenvolvimento é uma experiência singular, pessoal e individual que é resultado de vivências em diferentes contextos, a exemplo da família, escola, vizinhança, grupo de amigos, colegas de escolas que frequentam instituições religiosas ou não. Entende-se que a religiosidade é expressão da "própria experiência humana, atentando-se para o modo como é vivida e relatada por cada sujeito e acolhendo-a no seu modo genuíno de existir e de expressar/manifestar-se no mundo circundante" ${ }^{6}$

A pesquisa de Streck, que teve como objetivo compreender a religiosidade na adolescência, demonstrou que as imagens antropomórficas do Deus da infância são

3 SENNA, S. R. C. M.; DESSEN, M. A. Contribuições das teorias do desenvolvimento humano para a concepção contemporânea da adolescência. Psicologia: Teoria e Pesquisa, Brasília, v. 28, n. 1, p. 101108, mar. 2012. Disponível em: <http://www.scielo.br/pdf/ptp/v28n1/13.pdf>. Acesso em: 30 jul. 2012.

4 SILVA, Eliane Moura da. Religião, Diversidade e Valores Culturais: conceitos teóricos e a educação para a Cidadania. Revista de Estudos da Religião, n. 2, 2004, p. 1-14. à p. 4.

5 VALENTE, Gabriela A.; SETTON, Maria G. Notas etnográficas sobre a religiosidade na escola. Cadernos CERU, São Paulo, v. 25, p. 179-195, 2014. à p. 180.

6 FREITAS, Marta H. Relações entre religiosidade e saúde mental em imigrantes: implicações para a prática psi. Psico-USF, Bragança Paulista, v. 18, n. 3, p. 437-444, set./dez. 2013. à p. 438. 
mantidas, nesta etapa de vida. ${ }^{7}$ As ideias acerca dessa divindade são definidas através do que aprenderam e ouviram falar na sua família, na sua comunidade de fé, no seu meio social. $\mathrm{O}$ estudo também demonstrou que adolescentes começam a questionar e duvidar de valores, do conceito de vida e de fé que são objetivados e reexaminados, sendo necessário, por isso, que eles tenham um espaço protegido na sua família, na escola, na sua comunidade, para dialogar sem sofrer preconceitos ou pré-julgamentos acerca do que entende como sentido da vida e de sua religiosidade.

Os adolescentes passam boa parte do seu tempo na escola e não se pode negar que as questões em torno da religiosidade e da religião estão presentes nesse contexto. Quanto a esse aspecto, a pesquisa de Valente e Setton identificou e analisou a presença/ausência da religiosidade na escola pública e verificou que a religiosidade está presente na escola de forma velada e naturalizada, mesmo quando não há oferecimento da disciplina Ensino Religioso. [...] “Tudo leva a crer que a religiosidade, além de ser tida como instrumento comum para o fortalecimento das práticas das docentes, é também uma estratégia que se encontra disponível, preenchendo uma lacuna institucional" ${ }^{8}$

O contexto escolar é marcado pela pluralidade; cada pessoa que perpassa esse ambiente tem características de "sua cultura, sua formação, sua etnia e sua religião e, portanto, a escola congrega em seu interior uma pluralidade, devendo ser um espaço privilegiado de discussão acerca de valores e princípios. Colocar em pauta tais discussões é o desafio que se impõe" ${ }^{9}$ Assim, não é simplório colocar em diálogo as questões que perpassam a temática da religiosidade em contexto escolar, notadamente marcado pelo multiculturalismo, com estudantes oriundos de diferentes nacionalidades e culturas, com diversidade de idiomas, culinária, religião, dentre outros elementos que lhes são próprios.

Na região de fronteira seca brasileira é comum a presença do multiculturalismo, sendo rotineiro encontrar pessoas com ideias, línguas, vestimentas, hábitos e religiosidade diferentes. As expressões e vivências da religiosidade agregam traços do contexto de convivência da pessoa, uma vez que "a origem cultural influencia a religiosidade". ${ }^{10} \mathrm{~A}$ cidade de Ponta Porã, no Brasil, faz limite com Pedro Juan Caballero, no Paraguai, consideradas cidades geminadas por serem cortadas pela linha de fronteira seca. As fronteiras do Mato Grosso do Sul compreendem a Repúblicas do Paraguai e do Estado

7 STRECK, Gisela I. W. Adolescentes e religiosidade: aportes para o Ensino Religioso na escola. Estudos Teológicos, v. 46, n. 2, p. 60-73, 2006.

8 VALENTE; SETTON, 2014, p. 193.

9 MARTINS, Sueli. A (in)diferença e (in)tolerância religiosa em escolas públicas municipais de Juiz de Fora. Sacrilegens, Juiz de Fora, v. 10, n. 2, p. 15-34, jul./dez. 2013. à p. 31. Disponível em: <http://www.uff.br/sacrilegens/files/2014/07/10-2-3.pdf>. Acesso em: dez. 2017.

10 FERREIRA, Ana V.; PINTO, Maria C.; NETO, Félix. Religiosidade e bem-estar em estudantes portugueses, moçambicanos, angolanos e brasileiros. In: II SEMINÁRIO INTERNACIONAL CONTRIBUTOS DA PSICOLOGIA EM CONTEXTOS EDUCATIVOS. Braga: Universidade do Minho, 2012. p. 1588. 
Plurinacional da Bolívia. Nesse Estado, há seis cidades-gêmeas e uma cidade trigêmea formada por Guaíra, Mundo Novo e Salto Del Guayra (Mapa 01: Cidade Gêmeas).

Mapa 01: Cidade Gêmeas

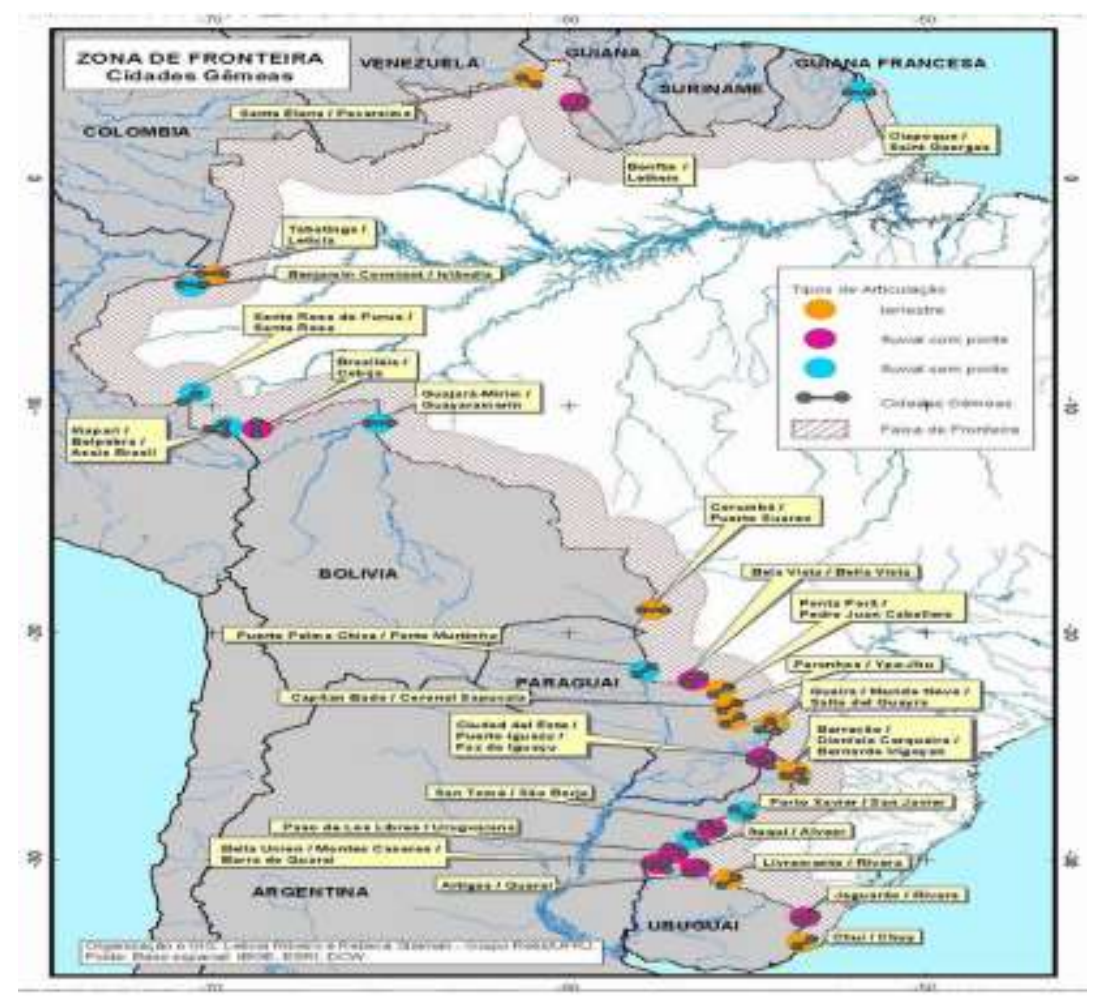

Fonte: STEIMANN, 2002.

A dinamicidade, interações sociais, políticas, econômicas e culturais que evocam conflitos e tensões são próprias das pessoas que vivem em regiões de fronteira seca. A determinação de fronteira não se restringe à delimitação específica de "início" e "fim" de uma cultura, ou seja, as áreas fronteiriças não são apenas demarcações físicas, mas podem representar locais de divergências culturais entre seus habitantes; também podem ser configuradas como locais de trocas interculturais que envolvem os consequentes hibridismos culturais. Assim, as fronteiras possuem grande complexidade analítica devido 
às relações e práticas sociais, políticas, culturais e econômicas que marcam a vida de seus moradores. ${ }^{11}$

Na cidade de Ponta Porã não apenas observam-se elementos da religiosidade do Brasil, mas também do Paraguai devido às relações e interações existentes entre os brasileiros e paraguaios dessa região. Cabe pontuar que a expressão da religiosidade paraguaia não se restringe a essa região de fronteira seca, mas ocorre em outras cidades do estado de Mato Grosso do Sul.

Especificamente no município de Dourados, Gardin observou que a expressão de religiosidade do povo paraguaio pode ser visível nos aspectos festivos da música, do canto e da dança tradicional da população, citando como exemplo parte das manifestações de devoção à Virgem Maria no dia oito de dezembro de cada ano. ${ }^{12}$ As novenas, realizadas no decorrer do ano, o terço que culmina no dia oito de dezembro de cada ano, a serenata à Virgem, no dia sete e madrugada do dia oito de dezembro durante a missa e as festividades com almoço dançante por um ou mais dias são elementos que expressam as tradições religiosas dos paraguaios, mesmo eles morando em território brasileiro.

Os elementos de sua tradição cultural estão fortemente presentes na celebração e nos festejos religiosos, a exemplo de uma missa rezada nos idiomas português, guarani e espanhol; "o primeiro em homenagem ao país onde a comunidade paraguaia se sedia e os demais por serem as línguas matrizes, originárias". ${ }^{13}$ Os aspectos da religiosidade de imigrantes paraguaios em Dourados se manifestam como a expressão de fé que se consuma por meio da mediação da música, da dança, da comida e dos próprios símbolos cívicos de seu país. ${ }^{14}$

Observa-se que existem peculiaridades na religiosidade dos paraguaios, o que torna interessante problematizar a religiosidade de estudantes no contexto brasileiro de fronteira, especificamente em Ponta Porã/Brasil. As escolas dessa cidade recebem um número considerável de estudantes paraguaios que têm cultura, costumes, crenças e elementos da religiosidade que podem ser diferentes dos estudantes brasileiros. A partir desse pressuposto, a presente pesquisa tem o objetivo de descrever a religiosidade de adolescentes no contexto de fronteira seca entre as cidades de Ponta Porã/Brasil e Pedro Juan Caballero/Paraguai sendo que, para isso, foram realizados os procedimentos metodológicos descritos a seguir.

\section{Procedimentos metodológicos}

11 NUNES, Flaviana G. Projetos de formação escolar para escolas em áreas de fronteira. Revista da ANPEGE, v. 7, n. 1, número especial, p. 205-216, out. 2011. Disponível em: <http://anpege.org.br/revista/ojs2.4.6/index.php/anpege08/article/view/156>. Acesso em: 15 maio 2016.

12 GARDIN, Cleonice. Religiosidade e simbologia de um povo: uma discussão sobre as festividades religiosas da Comunidade Paraguaia em Dourados. Revista Brasileira de História das Religiões, v. 1, 2010.

13 GARDIN, 2010, p. 5.

14 GARDIN, 2010. 
Essa pesquisa foi realizada na cidade de Ponta Porã, no Estado de Mato Grosso do Sul, com vinte e seis (26) estudantes, sendo doze (12) do sexo masculino e quatorze (14) do sexo feminino, com idades entre 12 e 13 anos, de uma turma do $7^{\circ}$ Ano do Ensino Fundamental I de uma escola estadual, localizada próxima à faixa de fronteira. Os participantes concordaram em participar do estudo mediante a assinatura e entrega do Termo de Consentimento Livre e Esclarecido (TCLE) e Termo de Assentimento (TA), conforme exigência do protocolo No 2.407.166 do Comitê de Ética em Pesquisa, da Universidade Federal de Mato Grosso do Sul. Nessa pesquisa foram utilizados dois instrumentos de coleta de dados descritos a seguir:

1. Questionário de Dados Sociodemográficos: composto por questões que possibilitam obter informações sociodemográficas do estudante, tais como idade, sexo, ano escolar, turma, sua origem identitária e a de seus familiares, ocorrência de repetência ou expulsão da escola e idioma que fala e escreve.

2. Escala de Religiosidade da Duke: composta por cinco itens que possibilitam mensurar três das principais dimensões do envolvimento religioso: religiosidade organizacional - que diz respeito à frequência a encontros religiosos -, religiosidade não organizacional - que inclui a frequência a atividades religiosas privadas -, e religiosidade intrínseca - diz respeito à busca de internalização e vivência da religiosidade como objetivo primordial da pessoa. ${ }^{15}$

A aplicação dos instrumentos ocorreu de maneira coletiva na própria sala de aula dos estudantes. Na ocasião, eles receberam instruções acerca dos procedimentos necessários para respondê-los e houve esclarecimentos das dúvidas surgidas no decorrer dessa atividade. As informações descritas pelos estudantes foram tabuladas e procedeu-se à sua análise, mediante a estatística descritiva simples. Os resultados foram organizados no formato de tabelas, discutidos à luz de pesquisas que abordam a temática em tela e apresentados na seção seguinte.

\section{Resultado e discussão}

A maioria dos participantes da pesquisa mora com os pais, sendo que apenas dois (2) moram com outras pessoas. A origem do pai de oito (8) adolescentes é paraguaia, mesmo número que relatou ter mãe de origem paraguaia, sendo que apenas um adolescente descreveu ter pai e mãe dessa mesma origem, ou seja, paraguaia.

A partir disso, observou-se que quinze (15) dos participantes têm pai ou mãe de origem identitária paraguaia, o que representa a maioria dos participantes. Dos vinte e seis (26) adolescentes, oito (8) deles relataram morar em Pedro Juan Caballero/PY e, apenas, um (1) se descreveu como brasiguaio, os demais todos se identificaram como brasileiros, mesmo tendo um dos pais de nacionalidade paraguaia e morando no Paraguai.

15 TAUNAY, Tauily et al. Validação da versão brasileira da escala de religiosidade de Duke (DUREL). Rev. Psiq Clín., v. 39, n. 4, p. 130-135, 2012. Disponível em: <https://www.revistas.usp.br/acp/article/viewFile/48262/52104>. Acesso em: set. 2017. 
Nesta região de fronteira brasileira é comum a constituição de laços e vínculos matrimoniais e familiares entre brasileiros e paraguaios. Assim, seus descendentes têm a oportunidade de ter dupla nacionalidade - brasileira e paraguaia. Mesmo não existindo vínculos afetivos, há paraguaios que escolhem a dupla nacionalidade, sendo comum a existência de crianças e adolescentes de origem familiar totalmente paraguaia que têm o registro de nascimento no Brasil.

As cidades de Ponta Porã e Pedro Juan Caballero são exemplos de interação no que se refere a questões socioculturais e estratégias de diferenciação e inserção de seus habitantes, com um constante fluxo de pessoas e de mercadorias, facilitado por ausência de barreiras físicas - como muros e cercas -, assim como naturais - como rios e montanhas. O cotidiano dessas cidades é caracterizado por várias relações que abrangem integração e separação, "apesar de constante contato, os moradores de ambas as cidades se veem submetidos a distintos poderes e cerceados pelos limites territoriais e jurídicos que caracterizam a jurisdição de cada país". ${ }^{16}$

Historicamente, as relações entre brasileiros e paraguaios é marcada pela Guerra do Paraguai. Soma-se a isso, a situação dos migrantes brasileiros no Paraguai em busca de terras, os denominados "brasiguaios"; o tratado de Itaipu - em 1973; os problemas relacionados aos entorpecentes na fronteira e a própria situação econômica do Paraguai que tem sua economia fragilizada dependente do comércio informal e também da produção agrícola, uma vez que quase $50 \%$ do seu PIB advêm dessa atividade. ${ }^{17}$

Cabe pontuar que a palavra brasiguaio é um neologismo que assume concepções diferentes. Há elementos históricos relacionados à imigração de brasileiros pobres para o Paraguai; assim, cronologicamente, a criação do termo data de 1985, na reunião de Mundo Novo/MS, em decorrência do retorno dos camponeses brasileiros para sua nação de origem. O adjetivo é atribuído, portanto, aos brasileiros grandes proprietários de terras no Paraguai, aos filhos de brasileiros que já nasceram no Paraguai, aos imigrantes e seus descendentes que, simultaneamente, têm traços culturais brasileiros e paraguaios e aos demais brasileiros que moram no Paraguai. ${ }^{18}$

Os pedrojuaninos se reconhecem com brasiguaios devido a diferentes elementos, como o fato de fazerem compras no Brasil, por casamentos com brasileiros, por morarem na região de fronteira, ou como "instrumento discursivo que objetiva dar sentido e

16 NASCIMENTO, Valdir A. Fronteiriço, Brasileiro, Paraguaio ou Brasiguaio? Denominações Indenitárias na Fronteira na Fronteira Pedro Juan Caballero (PY) e Ponta Porã (BR). ILHA, v. 16, n. 1, p. 105-137, jan./jul. 2014. à p. 116. Disponível em: <https://periodicos.ufsc.br/index.php/ilha/article/view/21758034.2014v16n1p105/28716>. Acesso em: 20 jun. 2016.

17 NASCIMENTO, 2014.

18 NASCIMENTO, 2014; ALBUQUERQUE, José L. C. A dinâmica das fronteiras: deslocamento e circulação dos brasiguaios entre os limites nacionais. Horizontes Antropológicos, v. 15, n. 31, p. 137-166, 2009. Disponível em: <http:/ /www.scielo.br/pdf/ha/v15n31/a06v1531.pdf>. Acesso em: 19 jul. 2016. 
significado às relações socioculturais estabelecidas no cotidiano da vida prática"19 e também em referência ao "sujeito que já frequentou escolas do Paraguai e atualmente estuda em escola brasileira". ${ }^{20}$

Nos espaços educativos dessa região de fronteira, observa-se fluxo de estudantes dos dois países. Assim, têm-se universitários nos cursos de medicina em Pedro Juan Caballero, no Paraguai, e crianças, adolescentes e jovens paraguaios que estudam em centros de educação infantil, escolas e universidades localizadas em Ponta Porã, no Brasil.

É possível sugerir que há encontros e/ou desencontros de idiomas, culinárias, vestimentas, músicas e religiosidade nos contextos educativos de ambas as cidades. Em relação ao aspecto religioso, em um contexto escolar de Ponta Porã/BR, foi verificada a religiosidade organizacional do universo de pesquisa de 26 adolescentes sendo que apenas um estudante não frequentava nenhuma instituição religiosa, a exemplo de igreja, templo ou outro encontro de caráter religioso (Tabela 01).

Tabela 01: Frequência dos adolescentes numa igreja, templo ou outro encontro religioso

\begin{tabular}{lccc}
\hline \multicolumn{1}{c}{ Opções de Resposta } & Origem & \\
& Brasileiro & Brasiguaio & Outra \\
\hline Mais do que uma vez por semana & 4 & - & 1 \\
Uma vez por semana & 10 & 1 & - \\
Duas a três vezes por mês & 3 & - & - \\
Algumas vezes por ano & 6 & - & - \\
Uma vez por ano ou menos & - & - & - \\
Nunca & 1 & - & - \\
\hline
\end{tabular}

Fonte: Autores, 2018.

A partir dos dados é possível sugerir que a religiosidade, ainda que de maneira indireta, aparece nessa escola de Ponta Porã/BR, tendo em vista que vinte e cinco (25) estudantes relataram frequentar uma igreja, templo ou outro encontro religioso. A pesquisa de Valente e Setton identificou a presença da religiosidade numa escola pública em duas turmas, uma do segundo e outra do quinto ano. ${ }^{21} \mathrm{~A}$ do segundo ano era mais heterogênea quando se tratava de religião, mesmo existindo estudantes de vários credos (católicos, cristãos, evangélicos, espíritas, kardecistas, sem religião).

19 NASCIMENTO, 2014, p. 128.

20 DALINGHAUS, Ione V. Alunos brasiguaios em escola de fronteira Brasil/Paraguai: um estudo linguístico sobre aprendizagem do português em Ponta Porã, MS. 164 p. Dissertação (Mestrado em Letras, Linguagem e Sociedade) - Unioeste, Cascavel, 2009. p. 51. Disponível em: <http://www.dominiopublico.gov.br/pesquisa/DetalheObraForm.do?select_action=\&co_obra=140320> . Acesso em: 01 abr. 2016.

21 VALENTE; SETTON, 2014. 
Os grupos religiosos com maior representação nas fichas pesquisadas (51 fichas) foram: católicos (22 alunos), evangélicos de diferentes denominações (12 alunos) e, em número menor, espíritas entre kardecistas e não especificados (7 alunos). Além disso, observou que, na sala das crianças mais velhas, expressões de linguagem acompanhadas de gestos religiosos eram observadas regularmente; já as crianças mais novas traziam elementos de sua religiosidade para o interior da escola, a exemplos de objetos como: pingentes com crucifixos, Bíblia para crianças, frases bíblicas escritas por parentes e um crucifixo de papel. ${ }^{22}$

A apreciação e a valorização do direito das pessoas de vivenciar a sua religiosidade implica no respeito à diversidade religiosa e a crenças variadas. A pesquisa com adolescentes da região de fronteira seca entre Ponta Porã/BR e Pedro Juan Caballero/PY sinalizou que as questões religiosas estão presentes no cotidiano dos estudantes, uma vez que a maioria, minimamente, vai uma vez por semana à igreja, templo ou outro encontro religioso. $\mathrm{O}$ adolescente brasiguaio vai uma vez por semana e o não identificado frequenta mais que uma vez por semana. Quatro (4) adolescentes brasileiros também apresentaram frequência de mais do que uma vez por semana a encontros religiosos, enquanto dez (10) brasileiros frequentam uma vez por semana.

Por outro lado, doze (12) adolescentes descreveram que se dedicam poucas vezes por mês, raramente ou nunca, a atividades religiosas individuais, como preces, rezas, meditações, leitura da Bíblia ou de outros textos religiosos. E dez (10) adolescentes assumiram que se dedicam diariamente a atividades religiosas durante o dia (Tabela 02).

Tabela 02: Frequência com que os adolescentes dedicam o seu tempo as atividades religiosas individuais

\begin{tabular}{lccc}
\hline \multicolumn{1}{c}{ Opções de Resposta } & Origem & Brasileiro & $\begin{array}{c}\text { Brasiguaio } \\
\text { Outra }\end{array}$ \\
\hline Mais do que uma vez ao dia & 4 & - & 1 \\
Diariamente & 5 & - & - \\
Duas ou mais vezes por semana & 2 & 1 & - \\
Uma vez por semana & 1 & - & - \\
Poucas vezes por mês & 10 & - & - \\
Raramente ou nunca & 2 & - & - \\
\hline
\end{tabular}

Fonte: Autores, 2018.

$\mathrm{Na}$ análise dos dados da religiosidade dos adolescentes nas instituições religiosas (Tabela 01) e em espaços não organizacionais (Tabela 02), observa-se um índice um pouco

22 VALENTE; SETTON, 2014. 
mais elevado da expressão da religiosidade nos espaços organizacionais/institucionais e coletivos, o que possibilita sugerir que as instituições religiosas influenciam as vivências e expressão da religiosidade dos adolescentes da região de fronteira seca entre Ponta Porã/BR e Pedro Juan Caballero/PY que participaram desta pesquisa. Cabe pontuar que a religiosidade é vivenciada de maneira singular pelos adolescentes; assim, a maneira de expressão de suas crenças, os hábitos religiosos, a adoração e as ideias que eles têm acerca da divindade podem ser parecidas, distantes e até mesmo contraditórias.

As imagens de Deus, na adolescência, são tão variadas, diferentes e até contraditórias como é diferenciado todo o processo de crescimento, de desenvolvimento da fé e de amadurecimento nesta fase de vida do ser humano. Adolescentes tanto podem falar de Deus como um velhinho de barba branca, sentado numa nuvem, como de um Deus mais pessoal, mais amigo e companheiro, que pode dar orientação, ajuda e apoio, como também podem afirmar que Deus não existe. Tanto podem acreditar em Deus, porque ele salva, ajuda em todas as horas, como afirmar que não acreditam, porque nenhum pedido feito foi atendido ou porque tudo não passa de uma invenção humana. Essas constatações demonstram que a fase da adolescência é um período de mudanças, de busca por uma compreensão e experiência pessoais a respeito de Deus. ${ }^{23}$

Em relação à internalização e vivência da religiosidade, a maioria dos adolescentes declarou que sente a presença de Deus ou do Espírito Santo em sua vida. Apenas, um (1) adolescente relatou que, em geral, não consegue sentir a presença de Deus na sua vida e outro descreveu não estar certo da presença divina na sua vida (Tabela 03).

Tabela 03: A presença de Deus (ou do Espírito Santo) na vida dos adolescentes

\begin{tabular}{lccc}
\multicolumn{1}{c}{ Opções de Resposta } & \multicolumn{2}{c}{ Origem } \\
& Brasileiro & Brasiguaio & Outra \\
\hline Totalmente verdade para mim & 15 & - & 1 \\
Em geral é verdade & 7 & 1 & - \\
Não estou certo & 1 & - & - \\
Em geral não é verdade & 1 & - & - \\
Não é verdade & - & - & - \\
\hline
\end{tabular}

Fonte: Autores, 2018.

A crença dos adolescentes em Deus tem relação com seus contextos de desenvolvimento. A pesquisa de Streck apontou que são variados os motivos que os adolescentes demonstraram para acreditar ou não em Deus, incluindo a vivência religiosa

23 STRECK, 2006, p. 69. 
na família ou na comunidade de fé, podendo, inclusive, reproduzir o discurso religioso que escutaram na comunidade de fé. ${ }^{24}$

A maioria dos adolescentes demonstrou que as crenças religiosas direcionam a maneira que eles vivem, sendo que treze (13) relatam que acreditam - no geral - serem verdade os dogmas transmitidos pela religião e que as suas crenças religiosas estão realmente por trás de toda a sua maneira de viver. Para oito (8) indivíduos, isso é totalmente verdade. Apenas, um (1) adolescente afirmou não ser verdade, em geral, que suas crenças religiosas estão, realmente, por trás de toda a sua maneira de viver (Tabela 04).

Tabela 04: As crenças religiosas dos adolescentes e sua maneira de viver

\begin{tabular}{lccc}
\hline \multicolumn{1}{c}{ Opções de Resposta } & Brasileiro & $\begin{array}{c}\text { Origem } \\
\text { Brasiguaio }\end{array}$ & Outra \\
\hline Totalmente verdade para mim & 7 & - & 1 \\
Em geral é verdade & 12 & 1 & - \\
Não estou certo & 4 & - & - \\
Em geral não é verdade & 1 & - & - \\
Não é verdade & - & - & - \\
\hline
\end{tabular}

Fonte: Autores, 2018.

Os adolescentes descreveram acerca dos esforços empreendidos para viver conforme a sua religião em todos os aspectos de sua vida. Observa-se que a maioria dos adolescentes busca internalizar e vivenciar a religiosidade como objetivo primordial de sua vida pessoal, ou seja, oito (8) deles consideraram ser totalmente verdade realizar muito esforço para viver a sua religião em todos os aspectos de sua vida; além desses, outros dez (10) apontaram que, em geral, é real o esforço para vivenciar a religiosidade. Apenas um adolescente considerou que não se esforça para viver a sua religião em todos os aspectos de sua vida (Tabela 05).

Tabela 05: Esforço dos adolescentes para viver a sua religião em todos os aspectos da sua vida

\section{Opções de Resposta}

\section{Origem}

Brasileiro Brasiguaio Outra

24 STRECK, 2006. 


\begin{tabular}{llll}
\hline Totalmente verdade para mim & 7 & - & 1 \\
Em geral é verdade & 9 & 1 & - \\
Não estou certo & 4 & - & - \\
Em geral não é verdade & 2 & - & - \\
Não é verdade & 1 & - & - \\
\hline
\end{tabular}

Fonte: Autores, 2018.

Esses resultados podem se relacionar com a ideia que os adolescentes têm acerca de Deus, como ser superior que possibilita cuidado, proteção, amizade, companheirismo, que é conselheiro e perfeito e, por isso, merece quaisquer renúncias e esforços para seguir esse modelo sobrenatural. Quanto a isso, a pesquisa de Streck apontou que os adolescentes identificaram Deus como

[...] pai de todos, que cuida e protege. Deus pai tem ainda outras qualidades como companheiro, amigo e conselheiro. Ele é o maior de todos, é luz e esperança. Deus pai é alguém "que nos conhece" e como alguém conhecido também é amado: "Deus é o pai, a pessoa que eu amo". O Deus pai está presente na vida e é possível saber o que esperar dele: "Deus é o pai de todos, ele é maravilhoso, podemos contar com ele para tudo". Assim como a mãe e o pai, também Deus tanto pode amar como castigar: "Deus é o nosso pai que pode tanto nos ajudar, como castigar". Deus também é o pai imaginário que protege, ajuda e também castiga a desobediência. Se Deus é aquele que julga e castiga, é também amoroso, fiel e misericordioso, é o "melhor amigo, é bondoso, que dá segurança e carinho"; "Deus é tudo, quem perdoa e sabe da verdade". "Deus é amor, um sentimento que dá bondade, consciência de certo ou errado". ${ }^{25}$

Em relação ao adolescente brasiguaio, observa-se que sua vivência da religiosidade é marcante, tanto nos aspectos organizacionais, pessoais quanto na expressão da religiosidade. Assim, uma vez por semana ele frequenta uma igreja, templo ou outro encontro religioso e duas ou mais vezes por semana realiza atividades religiosas individuais, como preces, rezas, meditações, leitura da Bíblia ou de outros textos religiosos. Além disso, sente a presença de Deus ou do Espírito Santo na sua vida, suas crenças religiosas estão realmente por trás de toda a sua maneira de viver e há muito esforço de sua parte para viver a sua religião em todos os aspectos de sua vida.

Mas os dados da pesquisa apontaram que os brasileiros também vivenciam essas mesmas características da religiosidade que o adolescente brasiguaio relatou. Mondardo analisou a relação entre brasileiros e paraguaios na fronteira entre Brasil e Paraguai, especialmente acerca da religiosidade nas cidades fronteiriças de Ponta Porã (Brasil) e Pedro Juan Caballero (Paraguai) e salientou que:

25 STRECK, 2006, p. 62-63. 
[...] existe um intercâmbio entre as paróquias da fronteira de Ponta Porã e Pedro Juan Caballero. Que o rito das missas é o mesmo nos dois países, mudando somente a língua, do português, para o espanhol. O guarani não participa da missa. É uma língua excluída, marginalizada, segundo o padre. Para o Padre, no Paraguai existem muitos feriados. Por isso, para ele "o paraguaio é preguiçoso". No entanto, nos diz que "o povo paraguaio é muito religioso", e, essa religiosidade passa para o lado brasileiro, pois, existem muitos paraguaios morando no Brasil. [...] O padre nos conta também que no Paraguai na Sexta Feira Santa não é feita comida nas refeições. Esta é feita um dia antes. Não se pode trabalhar neste dia. "Nem pentear o cabelo". "É coisa antiga, costume antigo". Fala ele que o povo do Paraguai é sofrido, e daí vem esta religiosidade maior, mais presente. [...] Quanto aos evangélicos no Paraguai, o padre nos diz que existem em menor proporção que no Brasil, mas que existem. ${ }^{26}$

Contudo, não é possível nos debruçarmos sobre a forma de expressão cotidiana das crenças, devoção, da religiosidade do brasiguaio que participou desta pesquisa. Mas, considerando as ideias de Gardin é possível que a música, a dança, o canto e a comida façam parte da expressão da religiosidade deste adolescente de origem paraguaia.

Realça-se com isso o significado da música e da dança na cultura paraguaia em que não se separa o festivo das práticas religiosas; muito ao contrário, reúnem-se na fé as mais importantes formas de expressão cotidianas, da festa, da alegria, da devoção, da crença, do pertencimento comunitário, da dança, da música, do canto, da comida, denotando aquilo que chamamos um modo paraguaio de ser. Há o entendimento de que, sendo a música um elemento forte na cultura paraguaia, ela deve continuar a existir como um elemento de reunião nas expressões de crenças religiosas por onde habitam os imigrantes. ${ }^{27}$

É possível que a vivência da religiosidade dos adolescentes brasileiros também seja expressa nos festejos, nas comidas, músicas e demais elementos simbólicos que estão associados a suas crenças. Há exemplos de elementos da religiosidade na região de fronteira brasileira, em Ponta Porã/BR com Pedro Juan Caballero/PY, como os crucifixos, Bíblia, frases bíblicas, imagens de santos, nas festas religiosas, na culinária, nos dias santos e feriados, como o Dia de São José, Padroeiro de Ponta Porã e demais elementos presentes no cotidiano dessa cidade brasileira de fronteira.

\section{Considerações finais}

De maneira geral, os dados apontam que os adolescentes no contexto de fronteira seca entre os municípios de Ponta Porã/Brasil e Pedro Juan Caballero/Paraguai,

26 MONDARDO, Marcos L. Da fronteira a "fronteiriça": observações do eu e do outro na (di) visão entre Brasil e Paraguai. BOCC. Biblioteca On-line de Ciências da Comunicação. p. 1-23, 2009. à p. 6. Disponível em: <http://www.bocc.ubi.pt/pag/mondardo-marcos-da-fronteira-a-fronteirica.pdf>. Acesso em: dez. 2017.

27 GARDIN, 2010, p. 6. 
participantes deste estudo frequentam instituições religiosas, acreditam em Deus, realizam ritos e se esforçam para vivenciar a religião em todos os aspectos de sua vida. Neste sentido, a religiosidade é um elemento que perpassa a vivência dos adolescentes, pois a maioria frequenta instituições de caráter religioso, se dedica a preces e orações e se esforça para viver sua vida conforme os preceitos religiosos.

Os distintos espaços sociais, culturais e religiosos, assim como as interações e relações que os adolescentes estabelecem nos contextos onde convivem devem ser considerados no desenvolvimento de sua religiosidade. "Parece ser mais prudente falar em religiosidade de adolescentes e não em adolescência", ${ }^{28}$ pois pesa a contribuição do contexto familiar, da comunidade e dos grupos com os quais os adolescentes convivem e que, possivelmente, influenciam a vivência e expressão de sua religiosidade.

\section{Referências}

ALBUQUERQUE, José L. C. A dinâmica das fronteiras: deslocamento e circulação dos brasiguaios entre os limites nacionais. Horizontes Antropológicos, v. 15, n. 31, p. 137-166, 2009. Disponível em: <http://www.scielo.br/pdf/ha/v15n31/a06v1531.pdf>. Acesso em: 19 jul. 2016.

BOCK, A. M. B. A adolescência como construção social: estudo sobre livros destinados a pais e educadores. Psicologia Escolar e Educacional, Campinas, v. 11, n. 1, p. 63-67, jan./jun. 2007. Disponível em: <http://www.scielo.br/pdf/pee/v11n1/v11n1a07.pdf>. Acesso em: 14 jan. 2012.

DALINGHAUS, Ione V. Alunos brasiguaios em escola de fronteira Brasil/Paraguai: um estudo linguístico sobre aprendizagem do português em Ponta Porã, MS. 164 p. Dissertação (Mestrado em Letras, Linguagem e Sociedade) - Unioeste, Cascavel, 2009. Disponível em: $<$ http://www.dominiopublico.gov.br/pesquisa/DetalheObraForm.do?select_action=\&co _obra=140320>. Acesso em: 01 abr. 2016.

FERREIRA, Ana V.; PINTO, Maria C.; NETO, Félix. Religiosidade e bem-estar em estudantes portugueses, moçambicanos, angolanos e brasileiros. In: II SEMINÁRIO INTERNACIONAL CONTRIBUTOS DA PSICOLOGIA EM CONTEXTOS EDUCATIVOS. Braga: Universidade do Minho, 2012.

FREITAS, Marta H. Relações entre religiosidade e saúde mental em imigrantes: implicações para a prática psi. Psico-USF, Bragança Paulista, v. 18, n. 3, p. 437-444, set./dez. 2013.

GARDIN, Cleonice. Religiosidade e simbologia de um povo: uma discussão sobre as festividades religiosas da Comunidade Paraguaia em Dourados. Revista Brasileira de História das Religiões, v. 1, 2010.

28 STRECK, 2006, p. 72. 
MARTINS, Sueli. A (in)diferença e (in)tolerância religiosa em escolas públicas municipais de Juiz de Fora. Sacrilegens, Juiz de Fora, v. 10, n. 2, p. 15-34, jul./dez. 2013. Disponível em: <http:/ /www.ufjf.br/sacrilegens/files/2014/07/10-2-3.pdf>. Acesso em: dez. 2017.

MONDARDO, Marcos L. Da fronteira a "fronteiriça": observações do eu e do outro na (di) visão entre Brasil e Paraguai. BOCC. Biblioteca On-line de Ciências da Comunicação. p. 123, 2009. Disponível em: <http://www.bocc.ubi.pt/pag/mondardo-marcos-da-fronteiraa-fronteirica.pdf>. Acesso em: dez. 2017.

NASCIMENTO, Valdir A. Fronteiriço, Brasileiro, Paraguaio ou Brasiguaio? Denominações Indenitárias na Fronteira na Fronteira Pedro Juan Caballero (PY) e Ponta Porã (BR). ILHA, v. 16, n. 1, p. 105-137, jan./jul. 2014. Disponível em:

$<$ https://periodicos.ufsc.br/index.php/ilha/article/view/2175-

8034.2014v16n1p105/28716>. Acesso em: 20 jun. 2016.

NUNES, Flaviana G. Projetos de formação escolar para escolas em áreas de fronteira. Revista da ANPEGE, v. 7, n. 1, número especial, p. 205-216, out. 2011. Disponível em: <http://anpege.org.br/revista/ojs-2.4.6/index.php/anpege08/article/view/156>. Acesso em: 15 maio 2016.

OZELLA, S. Adolescência: uma perspectiva crítica. In: CONTINI, M. L. J.; KOLLER, S. H. (Orgs.). Adolescência e psicologia: concepções, práticas e reflexões críticas. Rio de Janeiro: CFP, 2002. p. 16-24. Disponível em: <http:// site.cfp.org.br/wpcontent/uploads/2008/01/adolescencia1.pdf>. Acesso em: 15 abr. 2012.

SENNA, S. R. C. M.; DESSEN, M. A. Contribuições das teorias do desenvolvimento humano para a concepção contemporânea da adolescência. Psicologia: Teoria e Pesquisa, Brasília, v. 28, n. 1, p. 101-108, mar. 2012. Disponível em:

<http://www.scielo.br/pdf/ptp/v28n1/13.pdf>. Acesso em: 30 jul. 2012.

SILVA, Eliane Moura da. Religião, Diversidade e Valores Culturais: conceitos teóricos e a educação para a Cidadania. Revista de Estudos da Religião, n. 2, 2004, p. 1-14.

STEIMAN, Rebeca. A geografia das cidades de fronteira: um estudo de caso de Tabatinga (Brasil) e Leticia (Colômbia). 117 f. Dissertação (Mestrado em Geografia) - Departamento de Geografia, Universidade Federal do Rio de Janeiro, Rio de Janeiro, 2002. Disponível em: <http:/ / www.retis.igeo.ufrj.br/wp-content/uploads/2011/06/2002-geografia-dascidades-de-fronteira-RST.pdf>. Acesso em: 25 jul. t2016.

STRECK, Gisela I. W. Adolescentes e religiosidade: aportes para o Ensino Religioso na escola. Estudos Teológicos, v. 46, n. 2, p. 60-73, 2006.

TAUNAY, Tauily et al. Validação da versão brasileira da escala de religiosidade de Duke (DUREL). Rev. Psiq Clín., v. 39, n. 4, p. 130-135, 2012. Disponível em:

<https:/ / www.revistas.usp.br/acp/article/viewFile/48262/52104>. Acesso em: set. 2017.

VALENTE, Gabriela A.; SETTON, Maria G. Notas etnográficas sobre a religiosidade na escola. Cadernos CERU, São Paulo, v. 25, p. 179-195, 2014. 